\title{
ESPINOSA, ALEGRIA E CONHECIMENTO EM EDUCAÇÃO FÍSICA
}

\author{
Conrado Augusto Gandara Federici \\ Universidade Federal de São Paulo, Santos, São Paulo, Brasil \\ Marina Souza Lobo Guzzo \\ Universidade Federal de São Paulo, Santos, São Paulo, Brasil \\ Odilon José Roble \\ Universidade de Campinas, Campinas, São Paulo, Brasil \\ Vinícius Demarchi Silva Terra \\ Universidade Federal de São Paulo, Santos, São Paulo, Brasil
}

\begin{abstract}
Resumo
Estas são reflexões acerca da alegria como forma de conhecimento intelectual e teórico que compõe o amplo campo da Educação Física, como pressuposto fundamental do sujeito ao lançar-se à ação corporal e suas repercussões na ainda mais complexa área da Saúde. O objetivo do texto é ser introdutório à ideia de alegria expressa no pensamento do fi lósofo seiscentista Espinosa, como disparador de ressonâncias entre Educação Física e Saúde. Foi realizada uma análise da obra "Ética", amparada por pensadores da Filosofia e da Educação Física. Chegou-se à infância como o modelo vivo das ideias de Espinosa, em que o entusiasmo da criação do mundo e da vida entra em acorde ressonante com a construção de uma forma de saúde, do corpo e sua educação, em maior liberdade e auto nomia.
\end{abstract}

Palavras-Chave: Educação Física. Saúde. Alegria. Espinosa.

\section{Introdução}

\begin{abstract}
Alegria é a passagem do homem de uma perfeição menor para uma maior (Spinoza, 2009, p.141).

Por isso toda alegria perfeita consiste na alegria de viver e somente nela (Rosset, 2000, p.21).
\end{abstract}

Alegria é lugar comum, é palavra ordinária do vocabulário contemporâneo, é exigência do sujeito moderno que se pretende saudável e inserido, é também direito e atributo desejável do bem-viver, é, pois, constância e impulso na história da humanidade, é pertencimento da vida. 
Antes de localizar o conceito de alegria do filósofo holandês do século XVII Bento de Espinosa ${ }^{1}$, é possível referir-se a ela como uma velha conhecida que nos acompanha desde muito tempo, mais presente e viva na infância e, talvez, paulatina e inexplicavelmente, mais relegada a um algum plano menos importante da produtiva vida adulta. Por quê?

Quem sabe até se a partir de certa idade não nos tornamos impermeáveis à alegria fresca e nova, e se as mais doces satisfações do homem maduro não serão apenas sentimentos de infância revivificados, brisa perfumada que nos envia em lufadas cada vez mais raras um passado cada vez mais distante? (BERGSON, 2001, p.50)

A alegria neste contexto é um posicionamento político. Ao se pensar nas relações do profissional de Educação Física contemporâneo com a Saúde é desejável a extensão do tema até bases filosóficas que auxiliem em sua estruturação fundamental. Ao se admitir a atuação da Educação Física em conjunto a outras especialidades de caráter historicamente clínico, emerge nova necessidade de revisitação até ideias já por demais naturalizadas da área, como por exemplo, a cisão mente-corpo e a valoração do espírito sobre a carne.

Partiremos de uma contextualização sobre a alegria em Espinosa, detendonos na apresentação de alguns de seus principais conceitos presentes na obra Éti$c a$. Em seguida, serão afinadas algumas das relações com a Educação Física, alcançando reverberações na Saúde. Encerram o texto apontamentos sobre práticas promissoras da Educação Física que levam em conta a alegria do ser e o entusiasmo pela vida.

\section{De que alegria, de que saúde se pensa?}

Este estudo inicial sobre alegria e Educação Física é sustentado pelo desejo de fomentar o profícuo trânsito de conhecimento entre domínios ainda afastados na produção teórica da área, aproximando pelo referencial da Filosofia, a Arte e a Saúde como campos mais abrangentes sobre o tema proposto.

Para se iniciar com uma experiência concreta, sobre um exemplo de ofício artístico específico em alegria (MASETTI, 2011), admite-se que há indícios suficientemente instigantes a respeito da contribuição da arte do palhaço na recuperação de pacientes em internação, que recorre a critérios, rigores e técnicas (WUO, 1999) nem um pouco distantes daquelas presentes em tratamentos de outras naturezas, apesar da ainda escassa produção científica sobre o assunto.

\footnotetext{
${ }^{1}$ A grafia do nome do filósofo, Espinosa ou Spinoza, foi mantida de acordo com o uso feito pelos diferentes autores e fontes ao se referirem a ele.
} 
Os pacientes mirins referidos recebem a visita dos múltiplos profissionais da área da Saúde, que cuidam, cada qual em sua especialidade, de partes dos pequenos corpos acamados: remédios são ministrados, veias são pulsionadas, nutrientes são balanceados, pulmões tapotados, passatempos, brincadeiras sugeridas, pais ao largo esforçando-se para acompanhar a lógica e o encadeamento dos tratamentos. Recebem, também, a visita de um "besteirologista" (MASETTI, 1998), após a qual a criança, por muitas vezes, simplesmente esquece. Esquece e sai da cama para espiar no corredor, a ver se o que se passou foi realidade, pois a sua realidade infantil é lúdica.

$\mathrm{O}$ artista, fingindo-se de médico, e a criança, fingindo acreditar, coexistem por alguns instantes em experiência de alegria, nada mais. Já é muito. Pela ótica infantil, já bastaria.

Cada campo do saber clínico é direcionado a uma competência específica, amplamente analítica. A competência da Arte, do palhaço de hospital neste exemplo, direciona-se ao ser integral, revolvendo o momento presente em ato de síntese, tocando o paciente em sua importância de vida.

Dentre os profissionais que têm adentrado ao hospital mais recentemente, cujas áreas de atuação ganham os contornos de práticas terapêuticas, o da Educação Física ainda carece de ampliação do entendimento sobre suas funções nestes novos espaços de trabalho. Antigos redutos de doença, promissores lugares de saúde. Seria possível?

A Educação Física, assim como várias formas de Arte, tem o jogo como um de seus temas específicos, não como meio de ação, mas como finalidade. Além do esporte, do treinamento, do exercício e da atividade física, há conhecimentos em Educação Física que se pautam pela mímese, expressão, ritmo, gestos e jogos cênicos, já bem definidos e sedimentados culturalmente.

O jogo tem como fundamentos básicos (HUIZINGA, 2008 e CAILLOIS, 1990) o desejo e a liberdade dos participantes. São características do estado de jogo a alegria da fantasia extracotidiana, regrada e indispensável para a manutenção do seu movimento e impulso, bem como o próprio impulso da vida, o desinteresse, gratuidade e inutilidade, a tensão e incerteza ilusória, porém compactuada entre os partícipes, a entrega e absorção, enfim, o esquecimento como uma lacuna do tempo.

Não se escolhe voluntariamente qualquer situação de doença.

Não é possível prescrever o jogo como terapia, uma vez que ele parte também do desejo do outro.

Então, como perceber o desejo alheio e poder jogar junto, cuidando, sem assolar a essência do ato do jogar?

Como promover o encontro potente entre paciente e jogo?

A experiência lúdica reduz-se, transforma-se em tratamento? Como? Por quê? 
O profissional da Educação Física habita o terreno da educação do corpo e seus sentidos, dos modos de assimilação das técnicas de relações sociais em jogo, dos trabalhos lúdicos coletivos, da aprendizagem das potências corporais de cada indivíduo, das possibilidades de encontro dos corpos em vida.

Trabalhando com o que pode um corpo, mais do que como o corpo deve agir, segundo o pensamento deleuzeano sobre Espinosa (Deleuze, 2002), há mais possibilidades de bons encontros, de boas misturas, de alegria.

Nestes espaços de superposição e confluências de saberes, há que se identificar concordâncias, diferenças e oposições, discernindo as ações que ressoem no conjunto do cuidado, saúde e valorização da vida em sua amplitude.

\section{Espinosa e Educação Física}

Como é possível a Filosofia do séc. XVII de Espinosa se encontrar com a Educação Física contemporânea? O salto não se faz sem o acompanhamento da crescente necessidade de compreensão dos paradigmas que não mais respondem aos desconfortos modernos e à liberdade que se ignora.

O período europeu do Renascimento gerou e retomou doutrinas de pensamento e tratados que se propagam até nossos tempos e espaços ocidentais, com vistas a explicações teóricas vastas sobre deus, natureza, ser humano, existência e liberdade, as coisas, os vícios e virtudes e o correto modo de viver. Naquele contexto, a ciência moderna emergia do cenário das especulações teológicas.

Talvez uma das formas de pensamento mais perenes tenha sido a do filósofo francês René Descartes, fundador da Filosofia Moderna, a respeito da supremacia da mente sobre o corpo. A ideia emblematizada pela máxima duvido, penso, logo existo presente no Discurso do Método de 1637 atravessou séculos e mares carregando o nobre espírito que transcende o mundo material, "apenas" habitando um subjugado corpo carnal.

$\mathrm{Na}$ Holanda, terra natal de Espinosa, prevalecia uma relativa liberdade intelectual em relação à França ou à Itália. Espinosa foi fortemente influenciado pelo pensamento de Descartes, que passou a maior parte de sua vida criativa neste país. As condições de surgimento da obra cartesiana eram dominadas por um poder católico. Seus pensamentos aritméticos e geométricos, casados aos ideais dogmáticos da certeza e segurança religiosa, dispersaram-se aos quatro ventos, desdobrando-se em muitas outras formas de conceber o mundo, para além do pensamento filosófico, alcançando a educação do corpo.

$\mathrm{Na}$ "Ética, Parte I - Deus", Espinosa, o filósofo da imanência, ou daquilo que está inseparavelmente contido na natureza de um ser, parte do deus como substância primária: proposição 15 - Tudo o que existe, existe em Deus, e sem Deus, nada pode ser concebido; proposição 20 - A existência de Deus e sua essência são uma única e mesma coisa $(2009$, p.23, 30). Não há no pensamento espino- 
siano um deus exterior e superior, da transcendência, conforme aquele das religiões cristãs.

A proposição 13 prossegue: O objeto da ideia que constitui a mente humana é o corpo, ou seja, um modo definido da extensão, existente em ato e nenhuma outra coisa $(2009$, p.61). Por todo um complexo raciocínio geométrico composto de proposições, demonstrações, escólios e corolários, axiomas e postulados, Espinosa valoriza da mesma forma mente e corpo, diferenciando-se do sistema dualístico cartesiano. Segundo o escólio da proposição precedente,

Compreendemos não somente que a mente humana está unida ao corpo, mas também o que se deve compreender por união de mente e corpo. Ninguém, entretanto, poderá compreender essa união adequadamente, ou seja, distintamente, se não conhecer, antes, adequadamente, a natureza de nosso corpo (Spinoza, 2009, p.61).

O lugar do corpo em Espinosa, por uma forma geométrica e cartesiana de pensar, é equiparado ao da mente, o que representa uma ampliação das concepções teóricas possíveis para a Educação Física moderna. Para o autor, "a mente e o corpo são um único e mesmo indivíduo, concebido ora sob o atributo do pensamento, ora sob o da extensão" (SPINOZA, 2009, p.71).

Segundo Deleuze (1978, p.12), a proposição anticartesiana de base, que exclui toda a possibilidade do cogito, aparece na Parte II da "Ética" em que Espinosa afirma que "nós não podemos conhecer-nos a nós mesmos, e nós não podemos conhecer os corpos exteriores, a não ser pelas afecções que os corpos exteriores produzem sobre o nosso", entendendo-se por afecção o estado de um corpo enquanto sofre a ação de um outro corpo.

A palavra afecção permanece no léxico da medicina:

É interessante notar que a medicina rubrica o termo afecção como qualquer alteração patológica do corpo. Pathos, que deu origem à palavra patologia, significa emoção, ou mais exatamente, aquilo que vem de fora do ser para dentro dele. Esse caminho de fora para dentro, resume o ser passivo assinalado por Espinosa. No entanto, em sua Ética, as afecções (como o desejo, a alegria, a esperança, o amor etc.) são coisas nascidas do ser ativo. Como se sabe, a medicina enveredou pelo caminho da ciência empírica moderna, muito mais baseada em Descartes do que em Espinosa. Esta diametral diferença de tratamento sobre esta palavra não é de menor importância quando notamos, por extensão, que o corpo, na filosofia de Espinosa, é matriz de ação e imanência do ser, enquanto que na medicina é objeto passivo que, em razão de sua suscetibilidade à ação externa, deve ser conhecido em seu sentido maquinal, a partir de sua re-

Pensar a Prática, Goiânia, v. 17, n. 1, p. 01-294, jan./mar. 2014 
lação estrita com estes fatores patológicos, reservando à volição um papel não determinante ou, no máximo, coadjuvante (ROBLE, 2008, p.75).

A partir deste ponto, a teoria de Espinosa envereda para a relação entre os corpos, para o encontro e suas lógicas de influências recíprocas baseadas nos afetos de alegria e tristeza, partindo de alguns axiomas e postulados bastante caros à Educação Física de todos os tempos (Ética, Parte II - A natureza e a origem da mente - 2009, p.62, 66):

Axioma 1. Todos os corpos estão em movimento ou em repouso.

Axioma 2. Todo corpo se move ora mais lentamente, ora mais velozmente.

Lema 1. Os corpos se distinguem entre si pelo movimento e pelo repouso, pela velocidade e pela lentidão, e não pela substância.

Postulados:

1. O corpo humano compõe-se de muitos indivíduos (de naturezas diferentes), cada um dos quais é também altamente composto.

3. Os indivíduos que compõem o corpo humano e, consequentemente, o próprio corpo humano, são afetados pelos corpos exteriores de muitas maneiras.

4. O corpo humano tem necessidade, para conservar-se, de muitos outros corpos, pelos quais ele é como que continuamente regenerado.

6. O corpo humano pode mover e arranjar os corpos exteriores de muitas maneiras.

Estas são algumas ideias de base presentes na "Ética" de Espinosa que se relacionam diretamente às escolhas que se faz nos campos da Educação Física e da Saúde. Dizem respeito diretamente às concepções das intervenções possíveis no corpo e para o ser humano em vida.

Quando se parte da potência do corpo, de suas capacidades, o enfoque para a inserção da Educação Física em Saúde é diretamente dirigido à vida e sua infinitude de arranjos e belezas. O objeto principal é o ser humano e seu vigor, a ser es tudado em suas relações: consigo mesmo - cuidados de si, práticas integrativas; com o outro - comunicação, linguagem e expressão dos corpos, sociabilização; com o meio - interação global, sistêmica e ecológica.

\section{Alegria em Espinosa}

Algumas das riquezas da Filosofia de Espinosa estão na simplicidade e objetividade de suas preocupações com a vida prática, como o entendimento sobre a busca de felicidade e os encontros entre os seres humanos, apesar de toda a complexidade envolvida em suas demonstrações. O par de afetos alegria-tristeza resume o comportamento humano essencial e permite seu intrincado desenvolvimento matemático, culminando na definição da constituição dos afetos humanos. 
Espinosa postula na Ética, Parte III - A origem e a natureza dos afetos (2009, p.99): O corpo humano pode ser afetado de muitas maneiras, pelas quais sua potência de agir é aumentada ou diminuída, enquanto outras tantas não tornam sua potência de agir nem maior nem menor.

A alegria será, para ele, um dos três afetos primários, além da tristeza e do desejo:

Assim, por alegria compreenderei, daqui por diante, uma paixão pela qual a mente passa a uma perfeição maior. Por tristeza, em troca, compreenderei uma paixão pela qual a mente passa a uma perfeição menor. Além disso, chamo o afeto da alegria, quando está referido simultaneamente à mente e ao corpo, de excitação ou contentamento; o da tristeza, em troca, chamo de tristeza ou melancolia (SPINOZA, 2009, p.107).

Deleuze (2002, p.106-107), a seu modo, expõe o cerne da teoria sobre a força dos encontros:

Ou o modo existente encontra outros modos existentes que convêm com ele e compõem a relação deste com a sua (por exemplo, de maneira muito diferente, um alimento, um ser amado, um aliado); ou então o modo existente encontra-se com outros que com ele não convêm e tendem a decompô-lo, a destruí-lo (um veneno, um ser odiado, um inimigo). No primeiro caso, a aptidão do modo existente para ser afetado é preenchida por afetos-sentimentos alegres, à base de júbilo e amor; no outro caso, pelos afetos-sentimentos tristes, à base de tristeza e de ódio. Em todos os casos, a aptidão para ser afetado é necessariamente preenchida, como ela deve sê-lo em função das afecções dadas (ideias dos objetos encontrados). Mesmo a enfermidade consiste nesse preenchimento (grifos nossos). Mas a grande diferença entre os dois casos é a seguinte: na tristeza, a nossa potência como conatus serve toda ela para investir a marca dolorosa e para repelir e destruir o objeto que a causou. A nossa potência está imobilizada e só pode reagir. Na alegria, pelo contrário, a nossa potência está em expansão, compõe-se com a potência do outro e une-se ao objeto amado. Eis porque, mesmo quando supomos constante o poder de sermos afetados, algo da nossa potência diminui ou é impedido por afecções de tristeza, aumenta ou é favorecido por afecções de alegria. Podemos dizer que a alegria aumenta a nossa potência de agir, e a tristeza a diminui (grifos nossos). E o conatus é o esforço para experimentar alegria, ampliar a potência de agir, imaginar e encontrar o que é causa de alegria, o que mantém e favorece essa causa; 
mas é também esforço para exorcizar a tristeza, imaginar e encontrar o que destrói a causa da tristeza. [...]

A potência de agir (Espinosa diz às vezes força de existir, def. geral dos afetos) do modo é, pois, submetida a variações consideráveis enquanto o modo existe, embora a sua essência permaneça a mesma, e sua aptidão para ser afetado se suponha constante. É que a alegria, e o que dela resulta, preenche de tal maneira a aptidão para ser afetado que a potência de agir ou força de existir aumenta relativamente; e de maneira inversa com a tristeza. $\mathrm{O}$ conatus é, pois, esforço para aumentar a potência de agir ou experimentar paixões alegres.

O conceito de conatus pode fazer referência ao encontro com situações que não se vinculam à natureza humana ou que dela em muito se distanciam, sejam elas pertencentes aos imperativos do mundo do trabalho, das relações interpessoais ou da busca incessante por uma saúde modelar, estimulando a individualidade a proteger-se, restaurar e persistir no esforço pelo prazer consciente da experiência da alegria.

Espinosa denomina o ímpeto de perseverança na vida, o esforço que cada ser humano investe na própria essencialidade como força de existir ou potência de agir: "há uma variação contínua sob a forma aumento-diminuição-aumento-diminuição da potência de agir de acordo com as ideias que se tem" (DELEUZE, 1978, p.8).

Segundo a definição de alegria, o que pode significar passar para um estado de maior perfeição? O conhecimento, para Espinosa, em seu sentido mais básico, denominado de primeiro gênero, forma-se a partir de "ideias-afecção". Afeto (affectus), que difere de ideia por não ser representativo, será, pois, "a variação contínua da força de existir, enquanto esta variação é determinada pelas ideias que se tem" (Deleuze, 1978, p.8).

A ideia será considerada como representação de qualquer coisa, de uma realidade objetiva, tanto mais perfeita quanto mais coincidir com sua realidade formal. "Há então uma realidade formal da ideia, isto é, que a ideia é qualquer coisa em si mesma, esta realidade formal é seu caráter intrínseco e é o grau de realidade ou de perfeição que ela envolve em si mesma" (Deleuze, 1978, p.7).

O conhecimento gerado pelas afecções não nos permite conhecer suas causas.

Deleuze mostra que, segundo Espinosa, uma afecção "indica a natureza do corpo modificado melhor do que o corpo modificante, e ela envolve a natureza do corpo modificante" (aula de 1978, p.10). O encontro, a boa mistura, promove o conhecimento, ainda que elementar ou de primeiro gênero, das naturezas dos corpos. "Os Outros: o melhor de mim sou Eles" (BARROS, 2009, p.73).

Como um trampolim para a ação, a alegria em Espinosa é mais vantajosa do que a tristeza, pois apela à própria busca do conhecimento de sua causa, pas- 
sando a um estado ativo. A tristeza, ao inverso, aprisiona-nos no estado de passividade.

\section{Ressonâncias entre Educação Física, alegria e saúde}

O fato é que ninguém determinou, até agora, o que pode o corpo, isto é, a experiência a ninguém ensinou, até agora, o que o corpo - exclusivamente pelas leis da natureza enquanto considerada apenas corporalmente, sem que seja determinado pela mente - pode e o que não pode fazer (SPINOZA, 2009, p.101).

A Educação Física, afinada à ideia de alegria espinosiana, fundamentalmente impulsiona para a ação e afasta da passividade. Não haveria, neste sentido, uma Educação Física do contragosto, da diminuição da capacidade de agir, do dever moral no comando do bom funcionamento corporal.

A Educação Física age como organizadora dos encontros, na medida em que trata dos sentidos e das experiências. Seu trabalho é com a educação dos sentidos em direção a "elevar ao máximo o poder de ser afetado" do indivíduo.

Para tanto, há que se conhecer os sentidos do corpo. A educação do autoconhecimento é tarefa da Educação Física. Há que se "entrar na posse formal dessa potência e a experimentar alegrias ativas" como explica Deleuze, entendendo os mecanismos deste tipo de conhecimento, do poder de ser afetado e das próprias intensidades.

A Educação Física, por meio dos conhecimentos acerca do corpo, aproxima desejos afins, fazendo vibrar o aumento da potência de agir do corpo, seja para fins de saúde ou não. Na racionalidade da Filosofia de Espinosa está pautado o esforço contínuo para o aumento desta potência, "para assegurar a si mesma [à pessoa racional] a alegria, a independência e a serenidade, que são as verdadeiras marcas da liberdade" (SCRUTON, 2000, p.35).

Mais do que saber alguns dos dados clínicos do cliente, como pressão sanguínea, peso, altura, índice de massa corporal, como uma analogia rasa à relação médico-paciente, o profissional da Educação Física pode, também, pelos olhos humanos da Arte, mirar a pessoa em vida e enxergá-la em síntese.

Um campo de saberes que, há milênios, estuda o ser humano em suas minúcias e complexidades típicas, sem apartá-lo da vida, é o Teatro, que desde sempre se preocupou em entender a humanidade e recriá-la no corpo de outro, deslocando os sujeitos e as situações, com muitos objetivos distintos no decorrer da história, como criar, expressar, comunicar, festejar, jogar e divertir, manifestar e protestar, dentre tantos outros.

A Educação Física também pode estudar profundamente e reconhecer sustentada pelos saberes sistematizados do Teatro e da expressão - inicialmente a sensibilidade da alegria, suas estruturas e técnicas, que, diversamente das técnicas 
medicalizadas e clínicas, não se descolam, tanto das pessoas envolvidas, quanto das situações da vida, pois emergem delas mesmas.

Riso não é sinônimo de alegria, como o choro não o é de tristeza. Para Espinosa, o riso é mera manifestação que se refere exclusivamente ao corpo, como o tremor, a palidez, o soluço, sem qualquer relação com a mente. Não se confunde com o afeto de alegria.

A inteligência de tipos e expressões distintas de alegria, através do riso, favorece a pessoa, o profissional de qualquer área, a se colocar junto, em pé de igualdade com o outro. Em alegria conjunta, a mistura confunde os desníveis humanos, as posições sociais não são mais determinantes de hierarquias de conhecimento e responsabilidade pelo antigo sentido correto da troca de informações talvez pouco relevantes.

A ideia da responsabilização de cada pessoa pela sua própria saúde, exclusivamente, é típica de nossos tempos de individualismo extremo. Este pensamento esbarra em diversas proposições da teoria espinosiana que admitem o ser humano como parte da natureza (SPINOZA, 2009, p.160):

Padecemos à medida que somos uma parte da natureza, parte que não pode ser concebida por si mesma, sem as demais.

A força pela qual o homem persevera no existir é limitada e é superada, infinitamente, pela potência das causas exteriores.

Não pode ocorrer que a Educação Física promova práticas que afastem o homem de sua natureza versátil, maleável e adaptativa, no sentido de reproduzir industrialmente exercitações que se assemelhem mais à mecânica, sem vínculos mínimos com os afetos e as paixões.

A força da natureza humana está nos encontros, hoje interrompidos durante atividades físicas por intransponíveis fones de ouvido que isolam cada indivíduo em sua própria máquina corpórea. Nas palavras de Espinosa (Parte IV da Ética - A servidão humana ou a força dos afetos, 2009, p.177): "o que é de máxima utilidade para o homem é aquilo que concorda, ao máximo, com sua natureza, isto é (como é, por si mesmo, sabido), o homem".

As tecnologias e a virtualidade tanto mais participam da natureza humana quanto favorecem a potência dos encontros, quanto mais impulsionam o afeto da alegria de humano para humano.

Espinosa advoga em favor do aumento do conhecimento e consciência sobre as coisas com as quais nos relacionamos e que estão fora de nós, impelidas por forças que, sabidamente, não somos capazes de compreender completamente. Por uma atenção permanente aos modos de viver, aumentando nossa potência, poderíamos "assegurar, na medida do possível, que as coisas que acontecem conosco sejam também produzidas por nós" (Scruton, 2000, p.39) no que tange à nossa própria saúde, discernindo entre bons e maus encontros. 


\title{
A Educação Física e o entusiasmo pela vida
}

A criança é e será sempre o exemplo a ser espelhado.

Nenhuma outra manifestação de vida, de entusiasmo e de potência preconizada por Espinosa pode ser melhor entendida do que os comportamentos íntegros manifestados na infância. A criança é o modelo vivo das ideias de Espinosa, enquanto manifesta corporalmente suas possibilidades e seus desejos ainda inalcançáveis.

Apesar dos extensos estudos realizados por diversas áreas do conhecimento, à criança ainda falta ser contemplada em sua preciosa espontaneidade. $\mathrm{O}$ valor da experiência da subjetividade e do corpo infantil em movimento e em formação simultâneos oferece campo de aprendizagem infinita.

A repetição, termo comum do vocabulário da Educação Física, pode ganhar novas tonalidades quando sentida através do modo infantil. A criança repete, impulsionada pelo prazer da novidade. A consecutividade é a chave da manutenção da alegria da tarefa: de novo. A surpresa que as sensações e mínimas diferenças provocam na sua própria constituição do corpo, em tempo real, garantem o esforço de se repetir o jogo, em ato.

A realidade lúdica infantil toca as notas de liberdade da servidão do tempo. A dimensão do estar presente, da passagem, é outra, e a rota entre passado, presente e futuro confunde-se.

A criança, em brincadeira, improvisa, no sentido de em primo viso, surpreender-se com as situações em que se revela seu próprio corpo em ato de alegria. É uma sucessão de bons encontros, de potencializações de afetos de alegria, provocando a permanência do desejo no mesmo prazer.

Como escapar do aprendizado que se faz sobre o corpo? Como fechar-se à constante vontade de alegria, natureza própria do ser humano?

A criança conhece seu corpo em ato e encanta-se ou, mais simplesmente, canta.

O entusiasmo da criação infantil do mundo e da vida entra em acorde ressonante com a saúde do corpo e sua educação. A Educação Física partilha de espaços de saberes comuns, ricos de alegria em potência e intensidade, dispostos a, sem dúvida, também participarem da construção desta forma de Saúde em maior liberdade e autonomia.

\section{SPINOZA, JOY AND KNOWLEDGE IN PHYSICAL EDUCATION}

\begin{abstract}
These are reflections about joy as a form of intellectual and theoretical knowledge that includes the large field of Physical Education, based on a fundamental assumption about
\end{abstract}


the importance of physical action, and its impact on the complex area of Health. The aim of the text is to be an introduction to the idea of joy expressed in the thoughts of the philosopher Spinoza, as a trigger for the connections between Physical Education and Health. An analysis of the work "Ethics" was completed, sustained by general works from Philosophy and Physical Education. It looked at chilhood as a model for Spinoza's ideas, where enthusiasm for the creation of the world and life are connected to a particular type of health, from the body and its education, based on greater freedom and autonomy.

Keywords: Physical Education. Health. Joy. Spinoza.

\section{SPINOZA, ALEGRÍA E CONOCIMIENTO EN LA EDUCACIÓN FÍSICA}

\section{Resumen}

Estas son algunas reflexiones sobre la alegría como forma de conocimiento intelectual y teórico del amplio campo de la educación física, como presupuesto fundamental del sujeto al lanzarse a la acción corporal y sus repercusiones en la aún más compleja área de la salud. El objetivo del texto es que sirva de introducción a la idea de la alegría presente en el pensamiento del filósofo Espinosa, como generador de resonancias entre la educación física y la salud. Se realizó un análisis de la obra Ética, llegando a la infancia como modelo vivo de las ideas de Espinosa en las cuales el entusiasmo de la creación del mundo y de la vida, entra en concordancia con la construcción de una forma de salud, del cuerpo y su educación, con mayor libertad y autonomía.

Palavras Clabe: Educación Fisica. Salud. Alegría. Espinosa.

\section{Referências}

BARROS, M. Livro sobre nada. Rio de Janeiro: Record, 2009.

BERGSON, H. O Riso. São Paulo: Martins Fontes, 2001.

CAILlOIS, R. Os Jogos e os Homens. Lisboa: Edições Cotovia, 1990.

CARDOSO, H. R. Espinosa: alegria e inteligência. Revista Alegrar, nº5, 2008. Disponível em <http://www.alegrar.com.br/05/TEXTOS_A_05/Espinosa.pdf $>$. Acesso em: 15 jul. 2011.

CARVALHO, Y. M. Saúde, Sociedade e Vida - um olhar da educação física. Revista Brasileira de Ciências do Esporte, Campinas, v.27, n.3, p.153-168, maio/2006.

DELEUZE, G. Aula sobre Espinosa de 24/01/1978. Webdeleuze - Les cours de Gilles Deleuze. 1978. Disponível em <http://www.google.com.br/url? $\mathrm{sa}=\mathrm{t} \& \mathrm{rct}=\mathrm{j} \& \mathrm{q}=\&$ esrc $=\mathrm{s} \&$ source $=$ web $\& \mathrm{~cd}=1 \& \mathrm{ved}=0 \mathrm{CCIQFjAA} \& u r \mathrm{l}=\mathrm{http} \% 3 \mathrm{~A}$ $\% 2 \mathrm{~F} \% 2 \mathrm{Fxa}$.yimg.com $\% 2 \mathrm{Fkq} \% 2 \mathrm{Fgroups} \% 2 \mathrm{~F} 17725200 \% 2 \mathrm{~F} 978687583 \% 2 \mathrm{Fname}$ 
\%2FCursos_Deleuze_Spinoza_062005.pdf\&ei=DyRbUKbfOoGg9QTJ14HICQ\& usg=AFQjCNE9Nj3jph53MeGhOWq2C0Qk-hHD8A\&cad=rja $>$. Acesso em: 02 fev. 2012.

. Espinosa - Filosofia prática. São Paulo: Escuta, 2002.

HUIZINGA, J. Homo Ludens. São Paulo: Perspectiva, 2008.

MASETTI, M. Soluções de Palhaços. Transformações na realidade hospitalar. São Paulo: Palas Athena, 1998.

. Ética da alegria no contexto hospitalar. Rio de Janeiro: Sinergia, 2011.

ROBLE, O. J. Transvaloração do corpo: notas para uma educação ético-estética. 2008. (Tese de Doutorado) - Faculdade de Educação, Universidade Estadual de Campinas, Campinas. 2008.

ROSSET, C. Alegria. A força maior. Rio de Janeiro: Relume Dumará, 2000.

SCRUTON, R. Espinosa. São Paulo: Editora Unesp, 2000.

SPINOZA. Ética. Belo Horizonte: Autêntica Editora, 2009.

WUO, A. E. O clown visitador no tratamento de crianças hospitalizadas. 1999. (Dissertação de Mestrado) - Faculdade de Educação Física, Universidade Estadual de Campinas, Campinas. 1999.

Recebido em: 04/12/2012

Revisado em: 29/04/2012

Aprovado em: 03/06/2013

Endereço para correspondência:

conradofederici@yahoo.com.br

Conrado Augusto Gandara Federici

Universidade Federal de São Paulo

Departamento de Ciências do Movimento Humano.

Rua Silva Jardim - 136 - Sala 206

Vila Matias

11015020 - Santos, SP - Brasil 